\title{
Insights into self-care behavior of patients with diabetes: Support using a computerized self-evaluation system
}

\author{
Sachiko Waki ${ }^{* 1}$, Yasuko Shimizu ${ }^{2}$, Natsuko Seto ${ }^{3}$, Mayumi Sugahara ${ }^{4}$, Yoshiko Yoshida ${ }^{5}$ \\ ${ }^{1}$ Nursing School of Medicine, Oita University, Oita, Japan \\ ${ }^{2}$ Division of Health Sciences, Graduate School of Medicine, Osaka University, Osaka, Japan \\ ${ }^{3}$ Kansai Medical University, Osaka, Japan \\ ${ }^{4}$ Nursing Department, Oita Prefectural Hospital, Oita, Japan \\ ${ }^{5}$ Nursing Department, Beppu Medical Center, Oita, Japan
}

Received: March 8, 2016

DOI: $10.5430 /$ jnep.v6n10p51
Accepted: May 10, 2016

URL: http://dx.doi.org/10.5430/jnep.v6n10p51

\begin{abstract}
Objective: In the present study, outpatients with diabetes were encouraged to perform self-evaluation in order to clarify their responses on how they perceived self-care and the significance they attached to it.

Methods: The approach of encouraging patients to perform self-evaluation was then qualitatively assessed. Five patients with diabetes performed the self-evaluation using a self-care evaluation scale displayed on a touch panel. All patients were then interviewed while referring to their responses. The study data were collected between June 2011 and April 2012 during outpatient visits scheduled once or twice a month. The data were analyzed using the total quality control method proposed by Jiro Kawakita (the "KJ Method").

Results: During their visits, the patients who performed the self-evaluation told the study investigators the following: 1) although they had tried to shut themselves off from the barriers posed by living with diabetes, they also seized opportunities to face them; (2) by recognizing their lack of self-confidence, they were motivated from their hesitation to take a step forward; (3) they had a willingness both to recognize the positive and negative aspects of living with diabetes and to adopt an objective view of self-care; and (4) they could communicate their needs and their own next step to medical personnel.

Conclusions: The way that these patients with diabetes perceived self-care and the significance they attached to it changed according to daily occurrences, life events, and response to treatment. The self-evaluation was an important activity in promoting the patients' self-development and independence, suggesting that awareness, understanding, and support for self-evaluation of patients with diabetes and evaluation by supporting nurses can, in the context of the patient-nurse relationship, give rise to mutual responsibilities and put patients on the road to achieving self-care firmly grounded in self-awareness and independence.
\end{abstract}

Key Words: Significance of self-evaluation, Deliberate behavior, Patient self-development, Self-care ability, KJ method, Diabetes nursing

\section{INTRODUCTION}

The increasing number of individuals with diabetes mellitus ${ }^{[1,2]}$ not only have to cope with the disease, but also are likely to experience a variety of issues in their daily lives. In a review of education standards on the self-management of diabetes, the American Diabetes Association reported a

*Correspondence: Sachiko Waki; Email: syamasit@oita-u.ac.jp; Address: Oita University Nursing School of Medicine, 1-1 Idaigaoka HasamaMachi, Yufu City, Oita 879-5593, Japan. 
four-fold increase in complications among diabetics who had not received formal education regarding how to practice self-care. ${ }^{[2,3]}$ This has led to a greater emphasis on educating diabetics to practice self-care, and in turn, the implementation of various educational programs. These practical education programs have shown that patients with diabetes need to make an individual effort in order control their blood glucose (BG) while maintaining their lifestyle ${ }^{[4]}$ and that one of the greatest challenges for health care professionals lies in meeting the ongoing individual needs and requests of patients with diabetes as they attempt to deal with their chronic condition. $^{[2,5]}$ Participating in their own care is therefore crucial for patients with diabetes, ${ }^{[2,6]}$ and to do this, a certain degree of independence is required. Self-care in diabetes is not only limited to performing a number of specific tasks; it also requires self-decision and management to the extent that the patient can act with purpose in any situation according to their own intentions and judgments.

Cognitive evaluation theory is regarded as a sub-theory of the self-determination theory proposed by Ryan and Deci (2000). ${ }^{[7]}$ The core characteristics of self-evaluation are as follows: (a) self-esteem; (b) generalized self-efficacy; (c) locus of control; and (d) emotional stability. ${ }^{[8,9]}$ This suggests that in order to completely internalize control and become independent, it is essential to control these traits and to grasp their significance and value internally. ${ }^{[7]}$ Self-evaluation is a concept that involves evaluating one's own behavior and attitudes; it is considered to be a crucial element of self-care built on independence and autonomy.

Previously-developed indicators for the self-evaluation of self-care among patients with diabetes include the following: a self-care behavior scale $;^{[10,11]}$ a self-care competence scale; ${ }^{[12-18]}$ a psychological and social factor scale; $;^{[19,20]}$ and a perceived competence for diabetes scale, which was developed from the perspective of self-motivation. ${ }^{[21]}$ Moreover, numerous studies on responses of patients with diabetes to participation in education programs have employed statistical methods using a variety of indicators, including the following: happiness; anxiety; depression; self-esteem; self-efficacy; self-care patterns; glycosylated hemoglobin levels; $;^{[4,22-24]}$ the relationship with health care personnel; ${ }^{[25]}$ understanding of self-care technology for self-monitoring blood glucose; ${ }^{[26]}$ and the relationship between self-care behavior and attitudes and diabetes pathology and psychology. ${ }^{[27,28]}$ The context of these studies often involves evaluation of educational programs not only through assessment by health care personnel, but also through more established psychological education programs, ${ }^{[29-34]}$ counseling techniques, ${ }^{[35]}$ autonomy support, ${ }^{[36,37]}$ and information technology (IT)based assistance ${ }^{[38,39]}$ while identifying patient response us- ing quantitative indicators. Although these studies involve self-reported care evaluations by patients in response to surveys and scales, few have considered the patient's internal and absolute evaluations.

Moreover, self-monitoring of blood glucose (SMBG) is an important technique in controlling BG, ${ }^{[40]}$ and research development on self-monitoring and self-awareness has highlighted the importance of not only assessing BG levels and identifying the cause of BG fluctuations, but also of investigating the association between personal quality-of-life and BG control based on self-reporting. ${ }^{[41,42]}$ While support is provided to patients in reviewing their BG levels and symptoms after hypoglycemic or hyperglycemic episodes, a comprehensive evaluation is an essential part of this review. Although health care professionals may be able to identify patients who struggle with self-management, they may also lack the psychological training to help these patients modify their behavior. ${ }^{[43]}$ The current inability to comprehensively leverage self-evaluation in support of patients with diabetes suggests that self-evaluation needs to be adopted before any developments in self-care can be expected.

Another important point is that self-care is a deliberate action, ${ }^{[44]}$ meaning that it is action geared towards an expected outcome based on a carefully-considered decision achieved through evaluative inquiry, introspection, and judgment. ${ }^{[44]}$ However, the habitual self-care behavior of long-term diabetes sufferers may also be repeated so often that it becomes a routine part of the day's activities performed without focus of attention. ${ }^{[44]}$ Therefore, to restore self-awareness, which enables independent behavior, encouraging self-evaluation is crucial.

In a previous study on the efficacy of self-evaluation of outpatients with diabetes, the reliability of a touch panel computer incorporating a self-care evaluation scale (touch panel self-care evaluation scale) was investigated from the perspective of self-care competence and IT utilization among patients with diabetes in an outpatient nursing setting, which is typically under-equipped and understaffed. The patients used the touch panel to perform self-evaluations while awaiting their medical examinations. ${ }^{[39,45,46]}$ In another study, nurses incorporated findings on the self-reported intentions and emotions of patients with diabetes into the assessment of education programs. However, questions remain as to how the patient, as the self-carer, perceived their own self-care evaluation, and whether they applied their findings to their own self-care. Research suggests that reviews of self-care are limited to quantitative analysis in the form of questionnaires on various aspects of self-care and support for patients with diabetes. ${ }^{[15,16]}$ It also suggests that if nurses can adopt an 
approach aimed at delivering a balance in the development of self-care of patients with diabetes and find a way to verbalize the thoughts and sentiments of these patients, then the resulting positive outcomes will provide patients with diabetes with an opportunity to re-evaluate their lives. ${ }^{[47]}$ Despite the fact that self-care is a deliberate behavior, it is averse to conscious, subjective perception, which means that self-evaluation is often done unconsciously and the patient is typically unaware of its necessity. Transforming selfevaluation into a quality, valid concept therefore requires patient awareness and a clear process of investigation. To the best of our knowledge, no studies have been conducted on how self-evaluation manifests as a deliberate behavior when it is performed using indicators that genuinely enable the patient to review their own self-care. It is essential for nurses to comprehend the nature of self-care and nursing care based on an understanding of the concept of deliberate behavior, ${ }^{[4]}$ and to understand the significance that patients with diabetes attach to their own illness and self-management, as well as how they achieve self-care, through their experiences of medical treatment and life events.

\section{Objective}

The present study sought to clarify changes in how patients with diabetes perceived their own self-care after being encouraged to evaluate it using a touch panel self-care evaluation scale.

\section{MethodS}

\subsection{Setting and participants}

The subjects were five patients with type 1 or type 2 diabetes at the ambulatory internal medicine department of a general hospital in Japan. The subjects responded to a longitudinal survey over 11 months to assess the situation of self-care due to the prompt to continue the self-evaluation.

The inclusion criteria were as follows: 1) Adequate cognitive ability to respond to the evaluation scale; 2) No history of mental illness; 3) Scheduled hospital visits that were compatible with the investigator's study schedule; 4) Variation in BG between well-controlled (approx. HbA1c 5\%-6\%), moderately-controlled (approx. HbA1c 7\%), and poorlycontrolled (HbA1c $\geq 8 \%$ ); 5) Variation in treatment (oral or self-injection); and 6) Variation in patient age and sex. Subjects were selected with the assistance of qualified diabetes nurses at the ambulatory internal medicine department.

\subsection{Intervention method}

The concept of self-evaluation support is to help patients with diabetes be able to reflect and think using certain information, and is geared towards facilitating self-care actions.

Published by Sciedu Press
The patients with diabetes were instructed to respond to the self-evaluation scale using the touch panel. Interviews were then conducted while referring to their responses. The patients were approached by three of the investigators, who were qualified nurses with fundamental knowledge and skills regarding self-care promotion.

Based on the results of factor analysis from previous studies, ${ }^{[39,45,46]}$ the touch panel self-evaluation scale comprises eight factors with a total of 42 items: coefficient of reliability for morale towards living: $\alpha=0.846$; self-decision: $\alpha=0.836$; internal locus of control: $\alpha=0.800$; autonomy motivation: $\alpha=0.754$; social independence: $\alpha=0.769$; emotional control of self-efficacy: $\alpha=0.832$; knowledge: $\alpha=0.852$; and use of medical personnel: $\alpha=0.565$. The main items are shown in Table 1. Responding to the touch panel self-evaluation scale took approximately 10 minutes, and out of a total score of 6 (1-6 points of a Likert scale), the resulting scores were then plotted on an 8-point radar chart, with each point representing one factor, and $\mathrm{HbA} 1 \mathrm{c}$ levels were plotted on a bar graph to generate an evaluation sheet. ${ }^{[39,45,46]}$

Table 1. Excerpts of the tool/question items in the touch panel self-evaluation scale

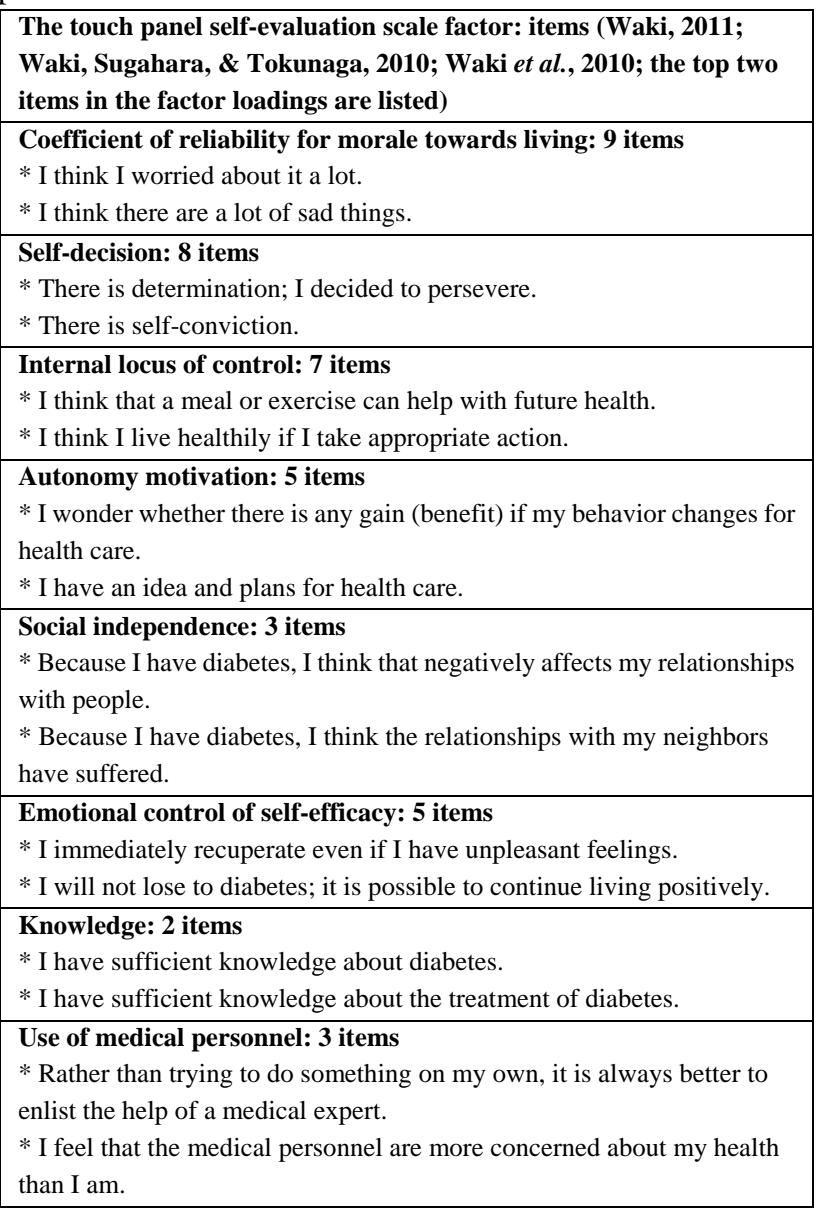


The interview confirmed the following six points while referring to variability of the patient's HbA1c levels and the patient's self-care evaluation score during the interview period:

(1) What reasons do you ascribe to your scores for each of the eight factors and the difference between your previous scores? Describe the current state of your self-care (acceptance of disease, reason for living, support, etc.)

(2) Describe your daily diet, exercise, and drug management regimens.

(3) What do you think about your HbA1c estimate and evaluation in relation to your daily lifestyle and selfcare status?

(4) Did you achieve your previous objective, and what currently motivates your self-care behavior? Do you have an objective that you hope to achieve before your next visit? If so, what is it?

(5) Did you notice or feel anything when performing the self-evaluation? If so, what was it?

(6) Are you worried or concerned about a certain aspect of your self-management? If so, what is it?

To minimize patient burden, each approach was conducted in less than an hour. The first step was to obtain patient consent to conduct the approach while they were waiting for their examination. This approval was sought when the patients came to the outpatient reception counter. Patients who provided their consent were then asked if they would be willing to respond to the touch panel self-care evaluation scale, and patients who answered in the affirmative were instructed to perform the self-evaluation and interviewed. We provided assistance to patients who had trouble viewing the scale or operating the touch panel, taking care not to influence their responses.

\subsection{Data collection}

The study data were collected from five patients over 11 months between June 2011 and April 2012 at outpatient visits scheduled once or twice a month. Although the patients were always asked to respond to both the touch panel selfcare evaluation scale and the interview, two of them did not respond to the intervention in some cases. Those cases were excluded from data analysis. The interview responses provided by patients during the approach were recorded on a designated form, and the details were later transcribed into an electronic file for use as study data. Any thick description in the collected data was noted.

\subsection{Summary of the participants' characteristics}

In the present study, patients with diabetes were encouraged to perform self-evaluation using the touch panel self-care evaluation scale for a period of about 1 year. Table 2 shows a summary of the participants' characteristics and the intervention method of the five patients (Cases A-E). The patients were two men and three women aged between 30 and 60 years old; four of the five patients had type 2 diabetes, and one had type 1 diabetes. Treatment consisted of oral hypoglycemic drugs in three of the four patients with type 2 diabetes, and insulin therapy in the 40-year-old man and the woman in her thirties with type 1 diabetes.

The study participants consented to undergo each interview, which was conducted while they awaited a physical exam or testing at the hospital's outpatient department. The interview was conducted 6 to 11 times, with the time required to respond to the self-care evaluation scale and interview ranging from 30 minutes to 1 hour depending on the respective content.

\subsection{Data analysis}

Data were analyzed using the qualitative synthesis method developed by Jiro Kawakita (the "KJ Method"). ${ }^{[4-50]}$ This method has been used in a broad range of fields, including education, nursing, industry and local and public administration. ${ }^{[51,52]}$ It is also occasionally referred to as the "affinity diagram" when used as a method to objectively organize data and ideas to reach a consensus on the priorities of qualitative data. The KJ method is an inductive, qualitative analysis method that seeks to identify meaning and substance from chaotic real-world conditions. Moreover, it depicts many of the elements of actual phenomena in a structured manner without abstraction. ${ }^{[48-50]}$ These are the benefits of the $\mathrm{KJ}$ method over other forms of inductive thematic analysis. Specifically, the KJ method is a systematic methodology in the social sciences involving the construction of theory through the analysis of data. It has also been used recently in nursing to decode hypothetically random, unexplained phenomena and form them into a relevant, rational framework. ${ }^{[50,51]}$ The KJ method involves three processes: (1) code making, (2) grouping, and (3) affinity diagram making. ${ }^{[48-51]}$

First, in each of the five cases, for (1) code making, ${ }^{[51]}$ the data obtained were unitized by focusing on issues experienced during self-care of patients with diabetes and by breaking down sentences into the smallest possible units so as not to eliminate the participants' thoughts. The unitized data were then identified as codes. This process is called code making. For (2) grouping, ${ }^{[51]}$ the codes were formed into groups based on similarities between the main themes under each code. After the initial grouping, a short summary was made to describe the essence of all codes belonging to each group. This was the first step in the process of grouping. The 
same process was repeated with these labels. The grouping formed, which were arranged spatially into a chart. process was repeated until approximately six labels were

Table 2. Summary of the participants' characteristics

\begin{tabular}{|c|c|c|}
\hline $\begin{array}{l}\text { Participants } \\
\text { (Sex; Age; Diabetes; Treatment; Frequency } \\
\text { of outpatient visits"; HbA1c"i") }\end{array}$ & Episode & $\begin{array}{l}\text { Number of } \\
\text { interventions }\end{array}$ \\
\hline $\begin{array}{l}\text { Case A } \\
\text { (Man; 60s; type } 2 \text { DM; OHA; 1/2; 5.9-6.2) }\end{array}$ & $\begin{array}{l}\text { Visited ophthalmologist } 3 \text { years prior with a complaint of poor vision. } \\
\text { Recommended to undergo surgery. Visited local clinic a few months earlier and } \\
\text { received diabetes medication. }\end{array}$ & 6 times \\
\hline $\begin{array}{l}\text { Case B } \\
\text { (Woman; 50s; type } 2 \text { DM; OHA; 1/1; 7.7-7.1) }\end{array}$ & $\begin{array}{l}\text { Lives with husband and son, works part-time making hospital meals. Undergoes } \\
\text { nutrition counseling once a month and maintains a food diary. No concomitant } \\
\text { illnesses. }\end{array}$ & 10 times \\
\hline $\begin{array}{l}\text { Case C } \\
\text { (Woman; 60s; type } 2 \text { DM; OHA; 1/1; 10.0- } \\
\text { 7.8) }\end{array}$ & $\begin{array}{l}\text { Weight: } 73 \text { kg. Diet and exercise therapy and oral medication were ineffective, } \\
\text { so self-injection of glucagon-like peptide- } 1 \text { was recommended; however, } \\
\text { patient started to refuse injections. Husband is deceased. Currently lives with } \\
\text { daughter and grandchild. Works at a company. Enthusiastic about career and } \\
\text { private life, and leads an energetic life. }\end{array}$ & 7 times \\
\hline $\begin{array}{l}\text { Case D } \\
\text { (Woman; 30s; type } 1 \text { DM; CSII; 1/1; 8.2-8.5) }\end{array}$ & $\begin{array}{l}\text { Lives with eldest son ( } 10 \text { years old) and eldest daughter ( } 6 \text { years old), works as a } \\
\text { part time kindergarten teacher. Parents live nearby. Separated from husband. }\end{array}$ & 10 times \\
\hline $\begin{array}{l}\text { Case E } \\
\text { (Man; 40s; type } 2 \text { DM; OHA; SC; 1/1; 9.8- } \\
\text { 10.3) }\end{array}$ & $\begin{array}{l}\text { Lives with wife and eldest son (primary school student). Worked at a factory at } \\
\text { time of 5th visit (incl. night shifts), but is currently facing retrenchment or } \\
\text { transfer to a remote location. Weight: } 98 \mathrm{~kg} \text {. }\end{array}$ & 7 times \\
\hline
\end{tabular}

Note. DM, diabetes mellitus; OHA, oral hypoglycemic agent; CSII, continuous subcutaneous insulin infusion, SC, subcutaneous.

${ }^{\dagger}$ Treatment: OHA, insulin self-injection (SC or CSII)

"Examination: frequency of outpatient visits (times per month)

${ }^{*}$ HbA1c (\%): Japan Diabetes Society, range during interview period; first visit-final visit

Thereafter, the results of these analyses were unified. In the overall analysis, all of the final labels of the five cases were combined into overall analysis code while maintaining their individuality and ensuring they did not become too abstract, and steps (1) and (2) were repeated. For (3) affinity diagram making ${ }^{[51]}$ the logical relationships between the labels in the final grouping were identified. The content of the labels in the final grouping were expressed in a short phrase, which became the descriptive theme assigned to the short summaries. These short summaries were used as the labels to symbolize in the final grouping (indicated by “"). This process is called affinity diagram making.

\subsection{Ensuring credibility and authenticity}

The main investigator had undergone a training program on the $\mathrm{KJ}$ method before performing the data analyses, and two investigators were instructors of the KJ method. The content and methodology of the analytical process were also supervised by investigators with expertise in diabetes nursing, as well as by qualified nurses and investigators with experience in qualitative research.

\subsection{Ethical considerations}

The study subjects provided written informed consent to participate in the study after receiving a verbal and written explanation of the study aims, a guarantee that their privacy Published by Sciedu Press would be protected, that their participation was voluntary, that their treatment would not be affected and they would not be penalized in any way if they chose to withdraw at any time. This study was approved by the ethics review board of the organization collecting the data.

\section{RESULTS}

First, the results of the repetitive grouping process to form the final grouping labels in the five cases are described. Regarding the individual analysis process of each of the five cases, a total of 35 codes and eight final labels were generated from the data for Case A; 63 codes and eight labels for Case B, 51 codes and seven labels for Case C, 50 codes and seven labels for Case D, and 45 codes and seven labels for Case E.

Regarding the overall analysis process, while maintaining their individuality and ensuring they did not become too abstract, 37 data units combining the final labels of the five individually-analyzed cases were selected as the original codes for the overall analysis. These codes were then grouped to obtain eight final labels. After obtaining the final labels, the data were structured and depicted in a diagram (see Figure 1) focusing on theoretical associations. After identifying theoretical associations, the theme to symbolize (indicated by " ") representing the properties of the final label was attached. 


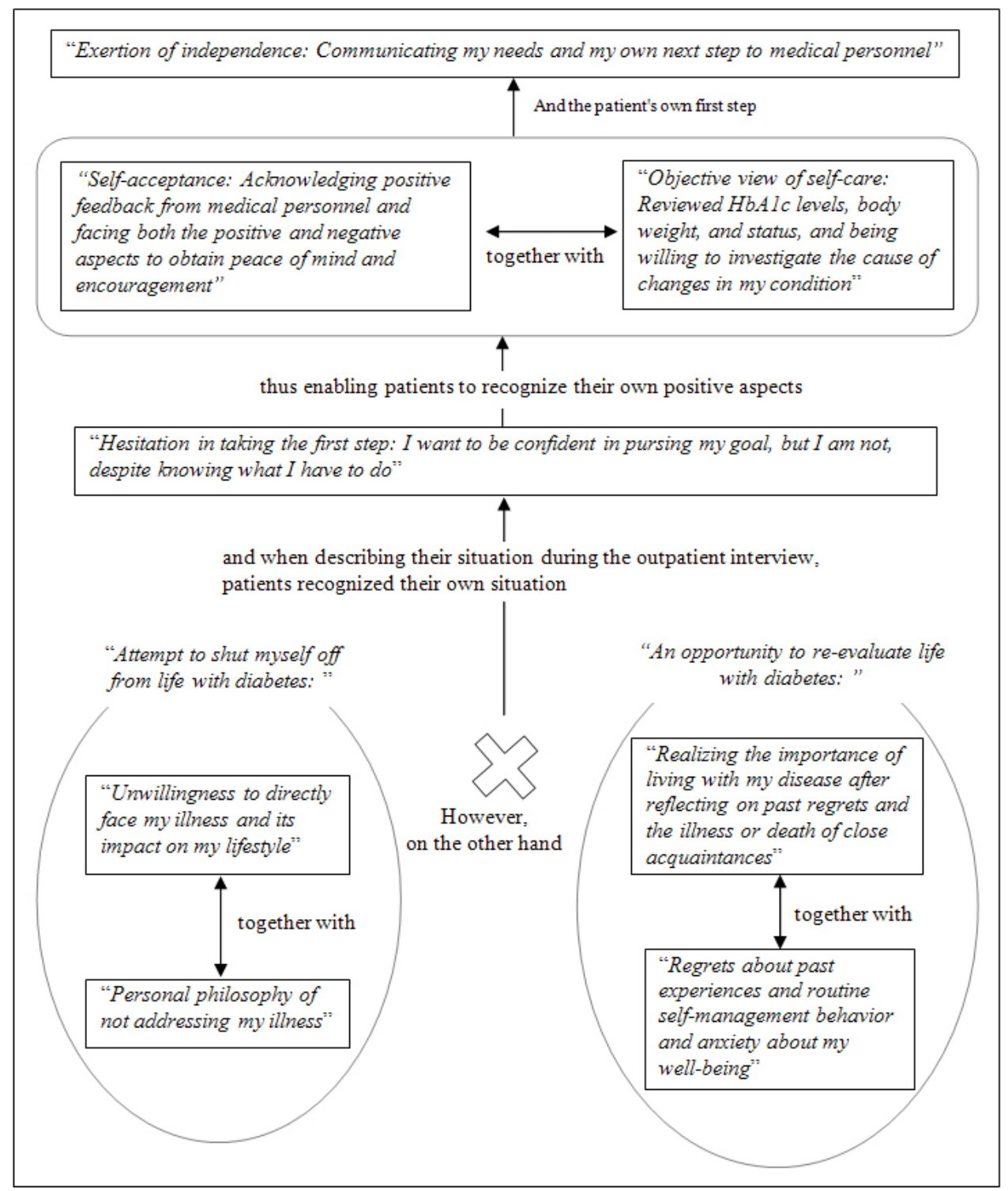

Figure 1. Affinity diagram of significance of self-care as perceived by patients with diabetes performing self-evaluation

3.1 The symbolized theme constituting the significance of self-care as perceived by patients with diabetes performing self-evaluation

Drawing on the results of the individual analysis representing exemplary traits of self-care in chaotic real-world conditions, an explanation of the overall analysis representing universal and nomothetic aspects of the objective-based meaning and essence of self-care is provided below for each theme to symbolize.

\subsubsection{Attempt to shut myself off from life with diabetes: Unwillingness to directly face my illness and its im- pact on my lifestyle}

After performing the self-evaluation, and while regarding $\mathrm{HbA1c}$ as the evaluative indicator, the patients with diabetes were shocked not only at their poor results, but also at feeling upset and regretful. They also stated they were indeed concerned by their diabetes during self-care. They described an unwillingness to face both their own inability to act despite realizing the need to do so, and the impact on their lifestyle, and admitted to not thinking too deeply even when concerned. These responses exposed a tendency not to acknowledge their life with diabetes.

In not thinking about my life with diabetes or in my daily life, I can think about work, life, goals and self-management, but generally do not choose to do so, and not eating and exercising properly to prevent my blood glucose from increasing means that I am not living a good 
lifestyle and that I am not a person who matters. Although I am concerned about my blood glucose level, my concern does not extend to thinking about it much. (Case E)

I am not concerned about my diabetes, but when it becomes clear that my food diary is incomplete, I am unwilling to accept the realization during meals that my condition has worsened, and that as more marks accumulate in my food diary, I do not want to acknowledge my failure to act, despite realizing that I should. (Case B)

\subsubsection{Attempting to shut myself off from life with diabetes: Personal philosophy of not addressing my illness}

While patients with diabetes also consider themselves as patients, they feel satisfied when they have the same spring in their step as that of their family and friends. Even with their illness, patients with diabetes feel that life is important, and they have found that they prefer not to dwell on the diabetes aspect of their life.

With the death of my husband, being busy with work, taking care of the family, and interacting with neighborhood friends, I was very reluctant to exercise, but I do not think this is bad,... I am energetic ... I am satisfied with the fact that I am able to work, so I think that is good. (Case C)

While I realize that diabetes may not be out of the ordinary, I am conscious of how I am viewed by society, so I do not go out of my way to talk about it to my family, workmates, or other members of the community. (Case E)

\subsubsection{An opportunity to re-evaluate life with diabetes: Re- alizing the importance of living with my disease after reflecting on past regrets and the illness or death of close acquaintances}

Looking at their score for the self-evaluation indicator of morale for living, the patients with diabetes had feelings of regret and responsibility based on their experiences of diabetes complications and the illness and death of close acquaintances. In contrast to their regular personal lives, these experiences led the patients to develop an awareness of the difficulty and gravity of living with a disease, and provided an opportunity to consider their life with diabetes.

I like all kinds of foods, but my wife is helping me to control the amount that I eat. Although I am not able to walk at the moment, I feel good when I exercise continuously, so sometimes I manage to adhere to my diet and exercise therapy, and other times I do not. I feel that my disease is like retinopathy in that I cannot neglect it, and that continuing to eat right and exercise is just as important as my work. (Case A)

Following the death of my mother and the news of the earthquake and tsunami, the meaning of life, death, and disease (diabetes) took on more weight for me as a person who cannot live without insulin. (Case D)

\subsubsection{An opportunity to re-evaluate life with diabetes: Regrets about past experiences and routine self- management behavior and anxiety about my well- being}

Patients regretted their complications that arose from disregard of their diet and other aspects of their lifestyle, and the fact that they were unable to properly self-manage their diet and exercise. Their HbA1c test results and worsening complications caused them to reconsider various things out of worry and anxiety for their well-being. On the one hand, reviewing their routine self-care caused them to close themselves off from their disease, but on the other hand, it gave them an opportunity to gain awareness about self-care.

I worried about what I would do if my HbA1c level (9\%-11\%) was poor, and felt despondent when medical personnel recommended needles and injections, which I do not like. I felt despair when thinking about the relationship between my medication, diet, and exercise, and became silent in my anguish. I can relate to the nurse's encouragement and always find myself anxiously dwelling on various matters. (Case C)

I previously weighed $75 \mathrm{~kg}$ and ate fatty foods. When I was diagnosed with diabetes, the doctor recommended that I undergo eye surgery immediately, which caused me to realize that my self-management had been poor from a while back. My weight loss of about $16 \mathrm{~kg}$ over the past 3 to 4 years was also due to diabetes, so I realized that if I had acted sooner, I would not have reached such a serious state. (Case A)

3.1.5 Hesitation in taking the first step: I wanted to be confident in pursuing my goal but was unable, despite knowing what I had to do

During their outpatient treatment, the patients with diabetes faced their own condition by speaking about wanting to shut 
themselves off from their disease and embracing the opportunity to think about their illness. They also spoke about the difficulty of not being able to self-manage their condition despite having the intention, will, and knowledge to do so. They blamed themselves for their weakness in giving up on or not being able to tolerate the self-care regimen, and had doubts as to whether they could maintain their self-care for a prolonged period. This recognition of their own lack of selfconfidence manifested as a hesitation to take a step forward.

My diabetes self-management would tend not to change due to my work commitments. Positive feedback from medical personnel would give me a minor sense of effort, but a lack of real accomplishment. (Case E)

My diabetes self-management would tend not to change due to snacking between meals, and a poor result in my HbA1c levels and body weight would inspire me to get back on track and try harder; this perceived lack of effort would rob me of my confidence. (Case B)

My ill-defined goals and personal efforts to improve my diet and exercise would inspire me in some way to take action. However, the established norms in my lifestyle and in the course of life events would prove to be a trigger for me giving up or becoming impatient, resulting in a perceived inability to stick at it for a prolonged period. (Case C)

\subsubsection{Self-acceptance: Acknowledging positive feedback from medical personnel and facing both positive and negative aspects to obtain peace of mind and encour- agement}

After the self-evaluation, when patients felt despondent, they were hesitant to take a first step, which led them to write down and review their HbA1c levels, diet, and how they felt while also receiving positive feedback from the nurse. After doing so, they felt physically relieved and were able to face both the positive and negative aspects of their life and selfmanagement, which was reassuring and encouraging. The patients were also better able to accept themselves and their diabetes.

I exercised for the first time in a while and felt good because I found it easier than I had expected. The last time I went for a walk, I noticed that I had lost weight. I started writing my food diary again and noticed that I was not eating enough vegetables, and made a mark in the diary on the times that I did not snack between meals. There were times when my weight and $\mathrm{HbA} 1 \mathrm{c}$ levels had decreased, and I tried to picture how my clothes would fit. When I start noticing my successes and failures, I am encouraged to try harder and put my goals into action. (Case B)

Being interviewed while responding to the scale caused me to reflect on the way that I tend to eat even when I know I should not, and the way that I fail to put my thoughts into action. This makes me want to try harder next time and reminds me that I need to act more responsibly. (Case B)

I feel happy and encouraged when my children and medical personnel show concern, when I receive positive feedback, and when $I$ have an opportunity to review my HbA1c levels, my diet, and my emotional state. (Case D)

\subsubsection{Objective view of self-care: Patients reviewed their HbAlc levels, body weight, and status, and became willing to investigate the cause of changes in their condition}

The patients with diabetes who performed self-evaluation tried to identify the reasons for fluctuations in their $\mathrm{HbA} 1 \mathrm{c}$ and weight targets while reviewing their lifestyle and selfmanagement behaviors, and even if some things did not turn out as planned, they considered the reasons and could still feel reassured and willing to make an effort. They viewed their self-care objectively and did not simply wait to be told what to do by the nurses; instead, they made their own choices and created their own motivation on what to do next.

I am making a genuine effort and meeting my obligations to achieve self-management behavior in terms of my blood pressure and weight monitoring and medication. (Case A)

Through a process of trial and error, by considering the reasons behind what was positive and what was negative, I am also thinking about the causes of fluctuations in my $\mathrm{HbA} 1 \mathrm{c}$ and weight targets from the perspective of lifestyle. (Case D)

Among the cases in the present study, one of the patients used their feelings of regret and responsibility at having developed diabetic retinopathy to undergo a strict objective self-examination based on a stringent $\mathrm{HbA} 1 \mathrm{c}$ target, and made a positive effort while also dealing with occasional feelings of potential failure. 
Amidst my various life events including work and raising my kids, I'm relieved to find that my HbA1c results are better than I had expected, and feel that my effort has paid off. (Case D)

Even when my HbA1c result is good, I either feel that I have been making an effort or that I have not been trying hard enough depending on the amount of exercise. (Case A)

When I do not exercise or I gain weight, when my drug therapy is good or bad, when my physical condition is poor, or when my HbAlc result is better or worse than expected, I experience a sense of regret that makes me want to try harder. (Case C)

I set my target $\mathrm{HbA} 1 \mathrm{c}$ level at under 6\%, and would think about the causes of any fluctuations around the $6 \%$ mark. (Case A)

\subsubsection{Exertion of independence: Communicating my needs and my own next step to medical personnel}

Although individual differences were evident among the patients with diabetes who performed the self-evaluation, during the interview, they became aware of their various emotions and the positive and difficult aspects of self-care, and were eventually able to express their requests to medical personnel and decide on treatment goals together, which led to taking their next step with the support of medical personnel.

At the annual company health checkup, I learned that my diabetes had deteriorated and was thus able to postpone my pending transfer, so I asked the doctor to write me a letter because it would not be good to avoid being transferred due to having a blood glucose level of $11 \%$, and I felt depressed at the thought of the stress that would come from being transferred to an unfamiliar location if I managed to temporarily lower my blood glucose. (Case E)

Undergoing specialized treatment such as insulin injections and meeting blood glucose targets is difficult, so, in addition to my own positive efforts, I also rely on the support of medical personnel, and in return, I give support to other patients and am determined to behave responsibly. (Case D)

I set a target and make a decision with the nutritionist or nurse to lose weight or keep a food diary. (Case B)
3.2 Significance of self-care as perceived by patients with diabetes performing self-evaluation: Theoretical narrative of overall analysis

The structural diagram was then read using the theme to symbolize, and a logical narrative was created. As propositional logic to be internalized into the structure diagram, patients showed three characteristic responses regarding their self-care.

The first characteristic was their "unwillingness to directly face my illness and its impact on my lifestyle" together with "a personal philosophy of not addressing my illness", which caused them to "attempt to shut themselves off from their life with diabetes". On the other hand, "realizing the importance of living with my disease after reflecting on past regrets and the illness or death of close acquaintances" together with "regrets about past experiences and routine self-management and anxiety about my well-being" gave some patients an opportunity to re-evaluate their life with diabetes. Through the self-evaluation, patients with diabetes learned that they were reconciling these mutually conflicting attitudes towards routine self-care.

The second characteristic was that after the patients with diabetes had performed self-care evaluation and had begun describing their situation to the investigator, they perceived a negative situation in which "they wanted to be confident in pursuing their goal but were unable to, despite knowing what they had to do," and that their "hesitation in taking the first step" also led them to acknowledge their own positive traits.

The third characteristic was that the patients "acknowledged the positive feedback from medical personnel and faced both positive and negative aspects to obtain peace of mind and encouragement", i.e., "self-acceptance". Patients also adopted an "objective view of self-care" and "reviewed their HbA1c levels, body weight, and status, and became willing to explore the cause of changes in their condition." They exhibited "exertion of independence", and also took their first step as a patient in "communicating their needs and their own next step to medical personnel."

\section{Discussion}

\subsection{Significance of facing the barriers posed by living with diabetes and controlling one's emotions as a re- sult of self-evaluation}

In the first logic, the patients with diabetes who performed the self-evaluation told the following to the study investigators during their outpatient visits: although they tried to shut themselves off from the barriers posed by living with diabetes, they also seized opportunities to face them.

The management of diabetes is largely dependent on patient 
self-care outside the control of those providing support, and previous study findings suggest that this makes diabetes management more complex. ${ }^{[53]}$ Obstacles to the empowerment of patients with diabetes, as demonstrated in a study on the grounded theory approach, include difficulty in diabetes care in the form of conflicting perspectives of "lifestyle" versus "illness", which disempowers both the patient and the specialist in terms of problem solving. ${ }^{[54]}$ In the present study, however, the obstacles that arose between self-management of diabetes and the patient's valued lifestyle provided glimpses of not only the aspect wherein patients attempt to shut themselves off from their disease, but also the independent aspect wherein patients take the opportunity to face their situation by embracing feelings of seriousness, regret, and anxiety. Forging a life with diabetes means that the person with diabetes makes a positive effort towards being independent. ${ }^{[54,55]}$

While the present study showed how patients with diabetes who performed self-evaluation responded to self-care, the question regarding the significance of this finding remains. Considering this question in the context of encouraging patients to undertake self-evaluation, previous research has shown that patients with more positive self-evaluations tend to select situations that are effective and avoid those that are not, and, as seen in the present study, patients with a negative self-evaluation due to the obstacles posed by self-care tend to experience more stress factors and perceive greater interference. ${ }^{[56]}$ Patients also reportedly experience self-evaluative emotions such as embarrassment due to negative norms and social contexts. ${ }^{[57]}$ The regret expressed by patients in the present study is an example of such emotions. The concept of regret is an emotion that affects individuals who feel compelled to reconsider their past choices in order to change their decision making. ${ }^{[58]}$ The fact that patients were encouraged to perform the self-evaluation caused them to perceive their evaluation in a negative light and to recognize their subsequent emotions. When describing these internalized emotions during their ambulatory visit, patients began to face their own situation.

To become independent, it is important to not only manage one's external environment, but also to develop an adaptive process for managing emotions and internal impulses, ${ }^{[7,59]}$ suggesting that supporting efforts towards independence also promotes internalization. ${ }^{[7]}$ Human emotions are also a potent source of energy for behavior, so a well-considered evaluation is one that involves controlling one's own emotions and having the strength to overcome barriers. ${ }^{[59]}$ Being encouraged to perform a self-evaluation and talking about one's self-care signifies the beginning of independence in terms of facing the barriers posed by living with diabetes and controlling one's emotions.

\subsection{Significance of acquiring motivation from hesitating to take a step forward after recognizing one's lack of self-confidence}

In the second logic, described as "Hesitation in taking the first step: I wanted to be confident in pursuing my goal but was unable, despite knowing what I had to do", patients had second thoughts about the barrier to live with diabetes, and accumulating power. From the beginning of independence in terms of facing the barriers posed by living with diabetes and controlling one's emotions, the willingness of patients to discuss their motivation for taking a step forward in their self-care arose from a willingness to face their negative trait of lacking confidence despite having the will and objective to act.

Working towards objectives enables a person to constantly assess whether they are moving forward and not veering from a desired path. Setting appropriate objectives will provide the criteria for evaluating behavioral outcomes. ${ }^{[59]}$ A lack of behavioral criteria and some form of evaluation will result in a lack of motivation and feelings of boredom, leading to instant gratification from external stimuli. ${ }^{[60]}$ This means that even having a goal may not result in advancement of one step. Individuals with a low sense of self-efficacy are susceptible to stressors ${ }^{[56]}$ and, as proposed by Brockner's theory of behavioral plasticity (1983) ${ }^{[56]}$ or Baumeister's model, ${ }^{[61]}$ individuals with low self-esteem are presumed to be more affected by their environment than those with higher selfesteem; by extension, patients with a low self-evaluation are more capable of adopting the opinions and advice of those around them. Responding to the self-evaluation scale and outpatient interview allows patients to consider the nurse's opinions and perspectives of the scale within the patientnurse relationship and to discover issues that they would not have seen on their own. It also means making a continued effort to compensate for the patient's lack of confidence in his or her own abilities. Moreover, patients who are uncertain about their self-evaluation act to change their current condition based on a desire to achieve a higher level of selfevaluation. This attitude entailed having second thoughts about the barrier to live with diabetes, and accumulating power. It could therefore be described as having provided the impetus for patients to take a step towards success.

\subsection{Significance of accepting oneself and having the will to take an objective view of self-care}

In the third logic, patients demonstrated a willingness both to recognize the positive and negative aspects and adopt an objective view of self-care, and to communicate their needs and their own next step to medical personnel.

Among the cases in the present study, as described for Case 
C, a partial trend was evident towards low self-evaluation caused by setting high $\mathrm{HbA} 1 \mathrm{c}$ targets and adopting a strict objective view of oneself. Setting overly-demanding standards in self-evaluation can give rise to a depressive response, chronic dejection, feelings of worthlessness, and intentional deficiency. ${ }^{[56,60]}$ Patients may therefore require support in setting realistic subordinate goals in order to achieve a positive self-evaluation. ${ }^{[60]}$ The effects of motivation tend not to be derived from the goal itself, but rather from the evaluative response to one's own behavior, so objectives are conditional requirements for achieving a positive self-evaluation. ${ }^{[60]}$ The internalization of overly-strict self-evaluation criteria is a persistent cause of individual anguish, ${ }^{[60]}$ and is also presumed to be an obstacle to the promotion of self-care. However, being aware of one's faults and recognizing the importance of continuity can be advantageous in a motivational sense, and this in turn can have an influence on the continuation of self-care. This motivation is also a result of an evaluative response to self-care that originates in a person's underlying emotions (i.e., regret and anxiety). Regardless of the type of evaluation process, the failure of outcomes to meet the designated criteria could in fact be due to the unsuitable nature of the criteria, so it is essential not to view this situation as grounds for criticism, but rather as a problem that needs to be resolved. ${ }^{[60]}$

Independent motivation will not arise if the patient's selfevaluation is too low. The self-evaluation therefore needs to be more moderate in order to translate to independent motivation and self-development. Noticing positive aspects, acknowledging certain positive personal traits, and having confidence while also refusing to rest on one's laurels and recognizing one's own shortcomings all serve to enhance the desire towards independent action. ${ }^{[59]}$ The patients with diabetes who performed self-evaluation tried to identify the reasons for fluctuations in their $\mathrm{HbA} 1 \mathrm{c}$ and weight targets, and even if some things did not turn out as planned, they considered the reasons and could still feel reassured and willing to make an effort. They viewed their self-care objectively and did not simply wait to be told what to do by the nurses; instead, they made their own choices and created their own motivation regarding what to do next while receiving nurse support.

Having the opportunity to record and review their HbA1c levels, diet, and emotional state provided the patients with diabetes with a pleasurable physical sensation, while positive feedback from medical personal and accepting both the positive and negative aspects of their situation gave patients a feeling of reassurance and encouragement. Individuals with a high level of self-esteem purportedly tend to express their lifestyle in meaningful ways, while those with low self- esteem tend not to have faith in their own knowledge and information, and substitute them for the knowledge and information of trustworthy experts and other individuals; they are therefore able to accept positive feedback. ${ }^{[56,61,62]}$ When an individual thinks about their future, feedback on the individual's strengths and weaknesses often functions as a valuable source of information. ${ }^{[63]}$ Uncertain self-evaluations characterized by accepting positive as well as negative aspects while both lacking and possessing confidence may also incorporate objective evaluations by medical personnel and inspire the patient to make an effort.

The stepping stone to change lies in self-acceptance and having concern for one's internal universe. It involves thinking about the reasons underlying a certain behavior coupled with an objective view of self-care. ${ }^{[59]}$ In the process of change, identifying the reason for problematic behavior can encourage a person to behave in a different way. ${ }^{[59]}$ Noticing both negative and positive aspects, accepting oneself, and adopting an objective view leads to an awareness of, and lends significance to, self-care.

\subsection{Significance of communicating one's needs and next step to medical personnel}

Finally, in the third logic, each of the patients in the present study showed "exertion of independence" and "communicated their needs and their next step to medical personnel" in their own way. Encouraging a future-minded approach reportedly has the benefit of enhancing the will to act, ${ }^{[64]}$ and clarifies what needs to be achieved and why the process of deliberation and introspection need to be incorporated, while the processes of introspection and judgment help to make decisions on what needs to be achieved based on current factors, conditions, and personal values. ${ }^{[44]}$ In other words, the fact that the patients with diabetes who performed the selfevaluation "communicated their needs and own next step to medical personnel" served to promote the independence and autonomy of their self-care as a deliberate behavior including the process up to that point.

A considerable amount of research has been conducted on the topic of support for independence. One finding of particular interest can be seen in the results of guided self-determination group training, which increased independence and patient enthusiasm to control their own BG through self-determination, although the lack of motivational results proved to be an issue. ${ }^{[37]}$ Despite the quantitative nature of its findings, a separate study reported that self-efficacy and self-evaluation are key targets in supporting patient independence in the context of improving dietary self-care. ${ }^{[36]}$ Previous research has also found that while the personnel providing support come from a clinical background, the patient's perspective 
is rooted in their own lifestyle, and that there are crucial differences in their respective goals, evaluations, and strategies. ${ }^{[65]}$ Another study has suggested that independence in patients with type 2 diabetes grows from nurse-patient and family caregiver-patient relationships, and that it grows from all aspects of lifestyle and chronic care regardless of the patient's diabetes. ${ }^{[54,55]}$ Accordingly, when using counseling methods and communication techniques to support patient independence, it is important for both the patient and the nurse to focus on self-evaluation.

\subsection{Study limitation}

A limitation of the present study is the small sample size, which led to only a small number of codes. To confirm the reproducibility of the present results, future studies will require a larger sample size.

\section{Conclusion}

The way that the patients with diabetes in the present study perceived self-care and the significance that they attached to it changed according to daily occurrences, life events, and response to treatment. Being encouraged to perform a self-evaluation and talking about one's self-care signifies the beginning of independence in terms of facing the barriers posed by living with diabetes and controlling one's emotions. Hesitation to move forward one step provided the impetus for patients to take a step towards the success of self-care. They therefore demonstrated a willingness both to recognize the positive and negative aspects and adopt an objective view of self-care, and to communicate their needs and their own next step to medical personnel. Supporting patient self-evaluations equated to supporting their independence and autonomy, and patients who recognized this support tended to focus on their own choices and accept themselves; they were also more likely to internalize the values derived within the context of these relationships. The findings also tended to suggest that self-evaluation motivates patients to be more independent in their future medical treatment and enhances their decision-making abilities. The self-evaluation was an important activity in promoting the patients' selfdevelopment and independence, suggesting that awareness, understanding, and support for self-evaluation of patients with diabetes and evaluation by supporting nurses can, in the context of the patient-nurse relationship, give rise to mutual responsibilities and put patients on the road to achieving selfcare firmly grounded in self-awareness and independence.

\section{ACKNOWLEDGEMENTS}

All authors contributed to the conception and design of this study; Sachiko Waki, Yasuko Shimizu, Mayumi Sugahara made substantial contributions to acquisition of data; Sachiko Waki1, Yasuko Shimizu, Natsuko Seto made substantial contributions to analysis and interpretation of data; Sachiko Waki, Yasuko Shimizu critically reviewed the manuscript and supervised the entire study process. All authors read and approved the final manuscript. The authors would like to thank the patients who participated in this study, and the teaching faculty and doctoral course qualified diabetes nurses at the Graduate School of Medicine, Faculty of Medicine, Osaka University, who supervised the study analyses. This research was supported in part by two Grants-in-Aid for Scientific Research (C) (22592445 and 25463413) from the Japan Society for the Promotion of Science.

\section{CONFlicts OF INTEREST Disclosure}

The authors have no potential conflicts of interest, financial or otherwise, to disclose. No funding has been received to conduct this study.

\section{REFERENCES}

[1] Guariguata L, Whiting DR, Hambleton I, et al. IDF Diabetes Atlas: Global estimates of diabetes prevalence for 2013 and projections for 2035. Diabetes Research and Clinical Practice. 2014; 103: 137 49. PMid:24630390. http://dx.doi.org/10.1016/j.diabres .2013 .11 .002

[2] Shrivastava SR, Shrivastava PS, Ramasamy J. Role of self-care in management of diabetes mellitus. Journal of Diabetes \& Metabolic Disorders. 2013; 12(1): 14. http://doi.org/10.1186/2251-6 581-12-14

[3] Mensing C, Boucher J, Cypress M, et al. National standards for diabetes self-management education. Diabetes Care. 2006; 29(Suppl 1): S78-S85.

[4] Holstein BE, Vesterdal JH, Sestoft L. Illness-behaviour, attitude, and knowledge in newly diagnosed diabetics. Danish Medical Bulletin. 1986; 33(3): 165-71. PMid:3720366
[5] Wagner EH, Austin BT, Davis C, et al. Improving chronic illness care: translating evidence into action. Health Affairs (Millwood) 2001; 20: 64-78. http://doi.org/10.1377/hlthaff .20.6.64

[6] UK Prospective Diabetes Study Group. Intensive blood-glucose control with sulphonylureas or insulin compared with conventional treatment and risk of complications in patients with type 2 diabetes (UKPDS 33). Lancet. 1998; 352: 837-53. http://dx.doi.org /10.1016/S0140-6736(98) 07019-6

[7] Ryan RM, Deci EL. Intrinsic and extrinsic motivations: Classic definitions and new directions. Contemporary Educational Psychology. 2000; 25(1): 54-67. PMid:10620381. http://dx.doi .org/10.10 06/ceps. 1999.1020

[8] Judge TA, Erez A, Bono JE, et al. The core self-evaluations scale: Development of a measure. Personnel Psychology. 2003; 56(2): 303-31. http://doi.org/10.1111/j.1744-6570.2003.tb00152.x

[9] Beauregard TA. Predicting interference between work and home: A comparison of dispositional and situational antecedents. Journal of 
Managerial Psychology. 2006; 21(3): 244-64. http://dx.doi.o $\mathrm{rg} / 10.1108 / 02683940610659588$

[10] Samuel-Hodge CD, DeVellis RF, Ammerman A, et al. Reliability and validity of a measure of perceived diabetes and dietary competence in African American women with type 2 diabetes. The Diabetes Educator. 2002; 28(6): 979-88. http://dx.doi .org/10.1177/0 14572170202800612

[11] Toobert DJ, Hampson SE, Glasgow RE. The Summary of Diabetes Self-Care Activities Measure: results from 7 studies and a revised scale. Diabetes Care. 2000; 23(7): 943-50. http://dx.doi.org/1 0.2337 /diacare.23.7.943

[12] Dolovich LR, Nair KM, Ciliska DK, et al. The Diabetes Continuity of Care Scale: the development and initial evaluation of a questionnaire that measures continuity of care from the patient perspective. Health \& Social Care in the Community. 2004; 12(6): 475-87. PMid:15717895. http://dx.doi.org/10.1111/j.1365-2524. $2004.00517 . x$

[13] Honjo K. Revision of the Self-Care Agency Questionnaire for patients with chronic illness. Japan Journal of Nursing Science. 2001; 21(1): 29-39. http://dx.doi.org/10.5630/jans1981.21.1_29

[14] Riesch SK, Hauck MR. The exercise of self-care agency: an analysis of construct and discriminant validity. Research in Nursing \& Health. 1988; 11(4): 245-55. http://dx.doi.org/10.1002/nur.47701 10406

[15] Shimizu Y, Kuroda K, Uchiumi K, et al. The development of an instrument to assess diabetes self-care agency - The revision of the instrument on the basis of the results. Journal of Japan Academy of Diabetes Education and Nursing. 2009; 13(2): 146-57.

[16] Shimizu Y, Uchiumi K, Asou K, et al. The reliability and validity of the Instrument of Diabetes Self-Care Agency (IDSCA). Journal of Japan Academy of Diabetes Education and Nursing. 2011; 15(2): 118-27.

[17] Sousa VD, Zauszniewski JA, Bergquist-Beringer S, et al. Reliability, validity and factor structure of the Appraisal of Self-Care Agency Scale-Revised (ASAS-R). Journal of Evaluation in Clinical Practice. 2010; 16(6): 1031-40. PMid:20626539. http://dx.doi.org/10. $1111 / j .1365-2753.2009 .01242 . x$

[18] Weinger K, Butler HA, Welch GW, et al. Measuring diabetes selfcare: a psychometric analysis of the Self-Care Inventory-Revised with adults. Diabetes Care. 2005; 28(6): 1346-52. http://dx.doi .org/10.2337/diacare.28.6.1346

[19] Fitzgerald JT, Davis WK, Connell CM, et al. Development and validation of the diabetes care profile. Evaluation \& the Health Professions. 1996; 19(2): 208-30. http://dx.doi .org/10.1177/016327879 601900205

[20] Resnick B, Luisi D, Vogel A, et al. Reliability and validity of the selfefficacy for exercise and outcome expectations for exercise scales with minority older adults. Journal of Nursing Measurement. 2004; 12(3): 235-48. http://dx.doi.org/10.1891/jnum.12.3.235

[21] Williams GC, Freedman ZR, Deci EL. Supporting autonomy to motivate patients with diabetes for glucose control. Diabetes Care. 1998; 21(10): 1644-51. PMid:9773724. http://dx.doi .org/10.2337 /diacare.21.10.1644

[22] Rubin RR, Peyrot M, Saudek CD. Effect of diabetes education on selfcare, metabolic control, and emotional well-being. Diabetes Care. 1989; 12(10): 673-79. http://dx.doi.org/10.2337/diacare .12 .10 .673

[23] Sloan FA, Padron NA, Platt AC. Preferences, beliefs, and selfmanagement of diabetes. Health Services Research. 2009; 44(3): 1068-87. PMid:19674433. http://dx.doi.org/10.1111/j.147 $5-6773.2009 .00957 . x$

Published by Sciedu Press
[24] Welch GW, Jacobson AM, Polonsky WH. The problem areas in diabetes scale: An evaluation of its clinical utility. Diabetes Care. 1997; 20(5): 760-66. http://dx.doi.org/10.2337/diacare.2 0.5 .760

[25] Amir S, Rabin C, Galatzer A. Cognitive and behavioral determinants of compliance in diabetics. Health \& Social Work. 1990; 15(2): 144-51.

[26] Gilden JL, Casia C, Hendryx M, et al. Effects of self-monitoring of blood glucose on quality of life in elderly diabetic patients. Journal of the American Geriatrics Society. 1990; 38(5): 511-15. http: //dx.doi.org/10.1111/j.1532-5415.1990.tb02399.x

[27] Pham DT, Fortin F, Thibaudeau MF. The role of the Health Belief Model in amputees' self-evaluation of adherence to diabetes self-care behaviors. Diabetes Educator. 1996; 22(2): 126-32. http: //dx.doi.org/10.1177/014572179602200205

[28] Wikblad KF, Wibell LB, Montin KR. The patient's experience of diabetes and its treatment: Construction of an attitude scale by a semantic differential technique. Journal of Advanced Nursing. 1990; 15(9): 1083-91. PMid:2229708. http://dx.doi.org/10.1111/j .1365-2648.1990.tb01990.x

[29] Alloway SC, Toth EL, McCargar LJ. Effectiveness of a group psychoeducation program for the treatment of subclinical disordered eating in women with type 1 diabetes. Canadian Journal of Dietetic Practice \& Research. 2001; 62(4): 188-92.

[30] Dellasega C, Gabbay R, Durdock K, et al. Motivational interviewing (MI) to change type 2DM self-care behaviors: A nursing intervention. Journal of Diabetes Nursing. 2010; 14(3): 112-18. PMid:24817822.

[31] Kroese FM, Adriaanse MA, Vinkers CD, et al. The effectiveness of a proactive coping intervention targeting self-management in diabetes patients. Psychology \& Health. 2013; 29(1): 110-125. http://doi.org/10.1080/08870446.2013.841911

[32] Mash RJ, Rhode H, Zwarenstein M, et al. Effectiveness of a group diabetes education programme in under-served communities in South Africa: A pragmatic cluster randomized controlled trial. Diabetic Medicine. 2014; 31(8): 987-93. PMid:24766179. http://dx.doi.org/10.1111/dme.12475

[33] Rosenbek Minet LK, Wagner L, Lønvig EM, et al. The effect of motivational interviewing on glycaemic control and perceived competence of diabetes self-management in patients with type 1 and type 2 diabetes mellitus after attending a group education programme: a randomised controlled trial. Diabetologia. 2011; 54(7): 1620-29. http://doi .org/10.1007/s00125-011-2120-x

[34] Spencer MS, Rosland AM, Kieffer EC, et al. Effectiveness of a community health worker intervention among African American and Latino adults with type 2 diabetes: A randomized controlled trial. American Journal of Public Health. 2011; 101(12): 2253-60. http://doi.org/10.2105/AJPH. 2010.300106

[35] Siebolds M, Gaedeke O, Schwedes U. SMBG Study Group. Selfmonitoring of blood glucose: Psychological aspects relevant to changes in HbA1c in type 2 diabetic patients treated with diet or diet plus oral antidiabetic medication. Patient Education and Counseling. 2006; 62(1): 104-10. PMid:16159705. http://dx.doi.o $\mathrm{rg} / 10.1016 / \mathrm{j} \cdot \mathrm{pec} .2005 .06 .013$

[36] Nouwen A, Ford T, Balan AT, et al. Longitudinal motivational predictors of dietary self-care and diabetes control in adults with newly diagnosed type 2 diabetes mellitus. Health Psychology. 2011; 30(6): 77179. PMid:21707174. http://dx.doi .org/10.1037/a0024500

[37] Zoffmann V, Lauritzen T. Guided self-determination improves life skills with type 1 diabetes and $\mathrm{A} 1 \mathrm{C}$ in randomized controlled trial. Patient Education and Counseling. 2006; 64: 78-86. PMid:16720089. http://dx.doi.org/10.1016/j.pec.2005.11.017 
[38] Nundy S, Lu CY, Hogan P, et al. Using patient-generated health data from mobile technologies for diabetes self-management support: provider perspectives from an academic medical center. Journal of Diabetes Science and Technology. 2014; 8(1): 74-82. PMid:24876541. http://dx.doi.org/10.1177/1932296813511727

[39] Waki S, Sugahara M, Tokunaga A, et al. Attempt to self-evaluate their self-care ability by diabetic outpatients and development of self-evaluation software in outpatient nursing. Obesity and Diabetes. 2010; 9: S79-87.

[40] Fritschi C, Quinn L, Penckofer S, et al. Continuous glucose monitoring: the experience of women with type 2 diabetes. Diabetes Educator. 2010; 36(2): 250-57. PMid:20016057. http://dx.doi .org/10.1177/0145721709355835

[41] Hernandez CA, Williamson KM. Evaluation of a self-awareness education session for youth education with type 1 diabetes. Pediatric Nursing. 2004; 30(6): 459-64. PMid:15704593.

[42] Hernandez CA, Hume MR, Rodger NW. Evaluation of a selfawareness intervention for adults with type 1 diabetes and hypoglycemia unawareness. The Canadian Journal of Nursing Research. 2008; 40(3): 38-56. PMid:18947091.

[43] Swanson V, Gold A, Keen A. Doing diabetes: an evaluation of communication skills and behaviour change training for health professionals. Practical Diabetes International. 2011; 28(3): 119-123a. http://dx.doi.org/10.1002/pdi.1573

[44] Orem DE. Nursing: Concept of practice (6th ed.). St. Louis: Mosby; 2001.

[45] Waki S, Sugahara M, Tokunaga A. The Reliability of the Instrument of a self-evaluation scale for self-care ability for outpatients with diabetes. Proceedings of the 15th Annual Meeting of the Japan Academy of Diabetes Education and Nursing. 2010; 14: 179 p.

[46] Waki S. Attempt to self-evaluate their self-care ability by diabetic outpatients and development of self-evaluation software in outpatient nursing. Poster session at the meeting of The 6th Japan-Korea International Nursing Conference and 2nd International Nursing Conference. Oita University: in October; 2011.

[47] Shimizu Y, Kuroda K, Uchiumi K, et al. Extraction of self-care agency elements for patients with diabetes - Toward development of nursing effect measurement tools. Journal of Chiba Academy of Nursing Science. 2005; 11(2): 23-30.

[48] Kawakita J. Hassoho. [Abduction]. Tokyo: Chuokoron-Shinsha; 1967.

[49] Kawakita J. Zoku Hassoho. [Abduction: Part two]. Tokyo: Chuokoron-Shinsha; 1970.

[50] Yamaura H. Theory and practice of the qualitative synthesis method (KJ Method) and "Cosmos Methodology" which creates conceptions The Japanese Journal of Nursing Research. 2008; 41(1): 11-32.

[51] Fukuda R, Shimizu Y, Seto N. Issues experienced while administering care to patients with dementia in acute care hospitals: A study based on focus group interviews. International Journal of Qualitative Studies on Health and Well-Being. 2015; 10: 25828. http://doi.org/10.3402/qhw.v10.25828

[52] Scupin R. The KJ Method: A technique for analyzing data derived from Japanese ethnology. Human Organization. 1997;
56(2): 233-37. http://dx.doi.org/10.17730/humo.56.2.x3 35923511444655

[53] Larme AC, Pugh JA. Attitudes of primary care providers toward diabetes: Barriers to guideline implementation. Diabetes Care. 1998; 21(9): 1391-96. http://dx.doi.org/10.2337/diacare.21.9. 1391

[54] Zoffmann V, Kirkevold M. Life versus disease in difficult diabetes care: Conflicting perspectives disempower patients and professionals in problem solving. Qualitative Health Research. 2005; 15(6): 75065. PMid:15961873. http://dx.doi.org/10.1177/104973230 4273888

[55] Mosera A, van der Bruggenb H, Widdershovenc G. Competency in shaping one's life: Autonomy of people with type 2 diabetes mellitus in a nurse-led, shared-care setting; a qualitative study. International Journal of Nursing Studies. 2006; 43(4): 417-27. PMid:16112674. http://dx.doi.org/10.1016/j.ijnurstu.2005.06.003

[56] Alexandra TB. Predicting interference between work and home: a comparison of dispositional and situational antecedents. Journal of Managerial Psychology. 2006; 21(3): 244-64. http://dx.doi.o $\mathrm{rg} / 10.1108 / 02683940610659588$

[57] Grob JD, Dijkstra A, de Groot C. How social context moderates the self-evaluative emotions experienced due to health risk behaviour. Psychology \& Health. 2011; 26(10): 1344-60. PMid:21598182. http://dx.doi.org/10.1080/08870446.2010.525638

[58] Cameron A. Regret, choice theory and reality therapy. International Journal of Reality Therapy. 2009; 28(2): 40-42.

[59] Deci EL, Flaste R. Why we do what we do: Understanding selfmotivation. New York: Penguin Books; 1996.

[60] Bandura A. Social learning theory. Upper Saddle River: PrenticeHall; 1977.

[61] Josephs RA, Bosson JK, Jacobs CG. Self-esteem maintenance processes: Why low self-esteem may be resistant to change. Personality and Social Psychology. 2003; 29(7): 920-33. PMid:15018679. http://dx.doi.org/10.1177/0146167203029007010

[62] Morrison L, Moss-Morris R, Michie S, et al. Optimizing engagement with Internet-based health behaviour change interventions: Comparison of self-assessment with and without tailored feedback using a mixed methods approach. British Journal of Health Psychology. 2014; 19(4): 839-55. PMid:24308806. http://dx.doi.org/10. $1111 / \mathrm{bjhp} .12083$

[63] Gervey B, Igou ER, Trope Y. Positive mood and future-oriented self-evaluation. Motivation \& Emotion. 2005; 29(4): 267-96. http: //dx.doi.org/10.1007/s11031-006-9011-3

[64] Hall PA, Fong GT, Cheng AC. Time perspective and weight management behaviors in newly diagnosed Type 2 diabetes: A mediational analysis. Journal of Behavioral Medicine. 2012; 35(6): 56980. PMid:22105339. http://dx.doi.org/10.1007/s10865-0 11-9389-6

[65] Hunt LM, Arar NH, Larme AC. Contrasting patient and practitioner perspectives in type 2 diabetes management. Western Journal of Nursing Research. 1998; 20: 656-76. http://dx.doi.org/10.1177 /019394599802000602 